\title{
ULTRAFILTRATION MEMBRANES FROM WASTE POLYETHYLENE TEREPHTHALATE AND ADDITIVES: SYNTHESIS AND CHARACTERIZATION
}

\author{
Smitha Rajesh and Zagabathuni Venkata Panchakshari Murthy* \\ Department of Chemical Engineering, Sardar Vallabhbhai National Institute of Technology, Surat 395007, Gujarat, India
}

Recebido em 12/09/2013; aceito em 03/12/2013; publicado na web em 27/03/2014

\begin{abstract}
The synthesis and characterization of asymmetric ultrafiltration membranes from recycled polyethylene terephthalate (PET) and polyvinylpyrrolidone (PVP) is reported. PET is currently used in many applications, including the manufacture of bottles and tableware. Monomer extraction from waste PET is expensive, and this process has not yet been successfully demonstrated on a viable scale. Hence, any method to recycle or regenerate PET once it has been used is of significant importance from scientific and environmental research viewpoints. Such a process would be a green alternative due to reduced raw monomer consumption and the additional benefit of reduced manufacturing costs. The membranes described here were prepared by a phase-inversion process, which involved casting a solution containing PET, $m$-cresol as solvent, and polyethylene glycol (PEG) of different molecular weights as additives. The membranes were characterized in terms of pure water permeability (PWP), molecular weight cut-off (MWCO), and flux and membrane morphology. The results show that the addition of PEG with high molecular weights leads to membranes with higher PWP. The presence of additives affects surface roughness and membrane morphology.
\end{abstract}

Keywords: polyethylene terephthalate; ultrafiltration; additive.

\section{INTRODUCTION}

A great deal of research has been conducted with the aim of understanding the mechanism of membrane formation by the phase-inversion process, which is the most commonly used technique for the preparation of asymmetric ultrafiltration (UF) membranes. The production of asymmetric ultrafiltration membranes is influenced by numerous factors, including the four components used in the process, i.e., polymer, solvent, nonsolvent, and additive. The presence of an additive plays a crucial role in adjusting membrane properties. The additives create a spongy membrane structure by preventing the formation of macrovoids, enhancing pore formation, improving pore interconnectivity, and introducing hydrophilicity. ${ }^{1}$ A significant amount of research has focused on the effect that different types of additives have on membrane morphology and performance. Previous studies revealed that the addition of polyethylene glycol (PEG) has a marked effect on the thermodynamic and kinetic control of the casting system, and it works as a pore reducer or macrovoid suppressor in most cases. Furthermore, PEG helps to provide a hydrophilic character to the resulting membrane, and increases in the additive concentration directly affect permeation flux and rejection rate. ${ }^{1-4}$

PET is used as a packaging material for containers and in the production of synthetic fibers. In this study, waste PET was used as-received without determining the polymer molecular weight distribution as this study aimed to recycle this material. The major drawback with using PET is that extraction of the monomer has not yet been demonstrated on a viable scale. If waste PET can be reused for different purposes, then the use of virgin plastic may be reduced, and this will, in turn, limit any adverse effect of the environment. Furthermore, a reduction in the demand for new PET through the reuse of waste material will reduce manufacturing costs and other factors that are detrimental to the environment, such as water usage, waste water discharge, emissions, and other waste. In the study, the potential application of waste PET to produce UF membranes was assessed, and the effects of an additive (PEG) on viscosity, pure

*e-mail: zvpm@ched.svnit.ac.in water permeability (PWP), solute separation, and flux and membrane morphology were investigated. Membranes manufactured with PET without additives are rigid and have poor mechanical properties. ${ }^{5}$ Thus, polyvinylpyrrolidone (PVP) was added, but this change alone did not improve the mechanical properties of the membranes sufficiently. PEG is a known and proven additive for membranes with a wide range of polymers. In this study, PEG was used as an additive. Changes in the concentration and average molecular weight $(\mathrm{Mw})$ of the added PEG were also studied by evaluating the performance of the resulting PET-UF membranes. The PEG concentration ranged from 10 to $30 \mathrm{wt} \%$ in the casting solution, and the average Mw was from $200 \mathrm{Da}$ to $600 \mathrm{Da}^{2-4}$ In addition, the PET membranes with PEG additives of different molecular weights were characterized by considering solute transport data, for which a sieving curve was obtained by plotting solute retention versus mass for each PET-UF membrane.

\section{EXPERIMENTAL}

\section{Materials and methods}

PET, which has an intrinsic viscosity ranging from 0.70 to 0.85 , was composed of waste material, and it was used without any further processing. $m$-Cresol, polyvinylpyrrolidone (PVP) $(90 \mathrm{kDa})$, and polyethylene glycol with molecular weights of 200, 400, and 600 Da were purchased from Sigma. Feed solutions were prepared using distilled water. Lithium bromide was obtained from Sigma. Dextran T-70 (70 kDa) and Dextran T-500 (500 kDa) were purchased from Pharmacia. Dextrans with average molecular weights of $162 \mathrm{kDa}$ and $298 \mathrm{kDa}$ were obtained from Sigma.

\section{Preparation of casting solution}

The casting solutions were prepared by dissolving a specific amount of PET in $m$-cresol, and the mixtures were stirred for $6 \mathrm{~h}$ at room temperature. PEG was added with continuous stirring until the solution was completely clear and homogeneous (45-60 min). PVP was slowly added to the clear casting solution with continuous 
stirring. The resultant polymer solutions were stored in glass bottles at room temperature to remove the air bubbles from the casting solution. The effect of the additives was investigated by preparing a range of casting solutions.

The viscosities of the different casting solutions were measured using a Brookfield viscometer at $25^{\circ} \mathrm{C}$ with a spindle rotation speed of $60 \mathrm{rpm}$. The casting solutions were selected on the basis of PEG concentration level and kept in the viscometer, and the shaft was mounted until the bubble was centered before each use and set the speed control to $60 \mathrm{rpm}$. The temperature of each sample was measured and an appropriate spindle was selected. Using the adjustment knob on the viscometer stand, the spindle was carefully lowered into the sample up to the immersion mark etched into the spindle shaft. The brake was released after $60 \mathrm{~s}$. The viscosity values were recorded, and they were converted to values in centipoise by multiplying the meter reading by the multiplier corresponding to the particular spindle used. The percentage of PET was maintained constant in the casting solutions. The compositions of the various casting solutions with different combinations of PEG, PET, and PVP are shown in Table 1.

Table 1. Composition of the PET ultrafiltration membrane casting solutions and their viscosities

\begin{tabular}{ccccccc}
\hline $\begin{array}{c}\text { PEG 200 } \\
(\mathrm{wt} \%)\end{array}$ & $\begin{array}{c}\text { PEG 400 } \\
(\mathrm{wt} \%)\end{array}$ & $\begin{array}{c}\text { PEG 600 } \\
(\mathrm{wt} \%)\end{array}$ & $\begin{array}{c}\text { PET } \\
(\mathrm{wt} \%)\end{array}$ & $\begin{array}{c}m \text {-cresol } \\
(\mathrm{wt} \%)\end{array}$ & $\begin{array}{c}\text { PVP } \\
(\mathrm{wt} \%)\end{array}$ & $\begin{array}{c}\text { Viscosity } \\
(\mathrm{cP})\end{array}$ \\
\hline 10 & 0 & 0 & 20 & 72 & 10 & 642 \\
0 & 10 & 0 & 20 & 72 & 10 & 860 \\
0 & 0 & 10 & 20 & 72 & 10 & 1150 \\
20 & 0 & 0 & 20 & 68 & 10 & 890 \\
0 & 20 & 0 & 20 & 68 & 10 & 1280 \\
0 & 0 & 20 & 20 & 68 & 10 & 1440 \\
30 & 0 & 0 & 20 & 64 & 10 & 1260 \\
0 & 30 & 0 & 20 & 64 & 10 & 1850 \\
0 & 0 & 30 & 20 & 64 & 10 & 2650 \\
\hline
\end{tabular}

The casting solution was poured onto a texlan fabric laid flat on a clean glass plate at room temperature. The solution was cast on a glass plate using a casting knife with the wet membrane thickness gap set at $152 \mu \mathrm{m}$ (6 mils). Immediately after casting, the glass plate with the cast film was dipped into distilled water at room temperature. The membrane casting speed was controlled by a D.C. motor set at $0.10 \mathrm{~m} / \mathrm{s}(20 \mathrm{ft} / \mathrm{min})$. The phase-inversion process started, and after a few minutes, a thin polymeric film supported on the texlan separated from the glass. ${ }^{5,6}$ The membrane was washed with distilled water and kept in a water bath prior to evaluation. All flat sheet membranes were visually inspected for defects, and good-quality areas were chosen for membrane evaluation.

\section{Ultrafiltration experiments}

Ultrafiltration experiments were performed using a cross-flow test cell at $275.6 \mathrm{kPa}(40 \mathrm{psig})$ and $25^{\circ} \mathrm{C}$. A membrane sample with an area of $22.12 \mathrm{~cm}^{2}$ was placed in the test cell with the active skin layer facing the incoming feed. The membrane was tested using distilled water for PWP. The water used for molecular weight cut-off (MWCO) determination was purified using an ion-exchange resin followed by distillation. Dextran samples with average molecular weights of 70, 162, 298, and $500 \mathrm{kDa}$ were employed for MWCO experiments. Dextran solutions were prepared by dissolving dextran in a $0.10 \mathrm{M} \mathrm{NaCl}$ solution buffered with phosphate at $\mathrm{pH}$ 7. The setup was run for $2 \mathrm{~h}$ to reach a steady state. The permeate flux was collected 6,12 , and 16 min after the test run was started. The refractive index (RI) of the permeate was determined $30 \mathrm{~min}$ after the permeate sample was collected. The dextran content in the feed and in the permeate was determined using an Abbe refractometer ( 0 to $10 \%$ ) at $25^{\circ} \mathrm{C}$ by measuring the RI of the permeate and feed against a blank and standard solution containing $0 \%$ and $1.0 \%$ dextran, respectively. The average MWCO of the test membrane is defined by the dextran sample that is rejected by $90 \%$ or more by the membrane. ${ }^{7}$

\section{Evaluation of membrane performance}

The PWP of the PET-UF membrane was calculated using the following equation: ${ }^{8}$

$$
P W P=\frac{Q}{A \cdot \Delta t}
$$

where $Q$ is the volume of the permeate (L), $A$ is the effective membrane surface area $\left(\mathrm{m}^{2}\right)$, and $\Delta t$ is the permeation time (h). The solute separation of the membrane was given by ${ }^{8}$

$$
R \%=\left[1-\left(\frac{C_{p}}{C_{f}}\right)\right] \times 100
$$

where $C_{p}$ is solute concentration in the permeate stream, and $C_{f}$ is the solute concentration in the feed stream.

\section{Scanning electron microscopy of PET/PVP ultrafiltration membranes}

Cross sections of the membranes were sputter-coated with gold using a Technic's Hummer 5 sputter-coater with a current of $15 \mathrm{~mA}$ for $3.5 \mathrm{~min}$. The coated membranes were viewed with a JSM 5300 scanning electron microscope with an accelerating voltage of $10 \mathrm{keV}$. To preserve the original dimensions of the pore and the porous structure of the membrane, the remaining water in the membrane was removed by a solvent-exchange process, which was carried out as follows. The wet membrane coupon was first soaked in pure isopropyl alcohol for $30 \mathrm{~min}$. The membrane coupon was subsequently soaked for $30 \mathrm{~min}$ each in isopropyl alcohol/hexane solutions (75:25, 50:50, and 25:75). Finally, the membrane was soaked in $100 \%$ hexane for $30 \mathrm{~min}$. Hexane within the membrane was removed under vacuum. ${ }^{9-11}$ Sample membranes to be examined by scanning electron microscopy (SEM) were cut out and fractured in liquid nitrogen. The dried fractured membrane samples were sputtered with gold, and then the cross-sectional scanning electron micrograph of each membrane was recorded.

\section{RESULTS AND DISCUSSION}

\section{Polymer solution properties}

The experimental results indicate that the basic membrane characteristics depend on the composition of the PET/PVP/PEG membrane casting solution. The effects of these changes are summarized in Table 2. It was observed that the use of different molecular weight PEG samples significantly affect the viscosity of the casting solution. Membrane casting solutions with 30\% PEG600, 10\% PVP, and 20\% PET had the highest viscosity, while the membrane casting solution with 10\% PEG200, 10\% PVP, and 20\% PET had the lowest viscosity. 
Table 2. Membrane characterization parameters

\begin{tabular}{|c|c|c|c|c|c|c|c|}
\hline $\begin{array}{l}\text { PEG } 200 \\
(\mathrm{wt} \%)\end{array}$ & $\begin{array}{l}\text { PEG } 400 \\
\text { (wt\%) }\end{array}$ & $\begin{array}{c}\text { PEG } 600 \\
(\mathrm{wt} \%)\end{array}$ & $\begin{array}{l}\text { PET } \\
(\mathrm{wt} \%)\end{array}$ & $\begin{array}{l}\text { PVP } \\
\text { (wt\%) }\end{array}$ & $\begin{array}{c}\text { Thickness } \\
(\mu \mathrm{m})\end{array}$ & $\begin{array}{c}\text { PWP } \\
\left(\mathrm{L} \mathrm{m}^{-2} \mathrm{~h}^{-1}\right)\end{array}$ & $\begin{array}{c}\text { Water content } \\
(\%)\end{array}$ \\
\hline 10 & 0 & 0 & 20 & 10 & 117 & 6.2 & 25 \\
\hline 0 & 10 & 0 & 20 & 10 & 120 & 6.8 & 27 \\
\hline 0 & 0 & 10 & 20 & 10 & 127 & 7.7 & 35 \\
\hline 20 & 0 & 0 & 20 & 10 & 130 & 38.2 & 28 \\
\hline 0 & 20 & 0 & 20 & 10 & 139 & 42 & 30 \\
\hline 0 & 0 & 20 & 20 & 10 & 147 & 86.2 & 37 \\
\hline 30 & 0 & 0 & 20 & 10 & 135 & 79 & 25 \\
\hline 0 & 30 & 0 & 20 & 10 & 137 & 92 & 35 \\
\hline 0 & 0 & 30 & 20 & 10 & 142 & 120 & 35 \\
\hline
\end{tabular}

The viscosities of the solutions increased with the presence of additives. An increase in the molecular weight of the additives led to an increase in the viscosity of the casting formulations. The viscosity of the polymer solution with PEG600 (30\%) as the additive was almost double that of the polymer solution with PEG600 (20\%). ${ }^{12}$ PVP is used as a plasticizer for ionophore membranes, and PEG600 is used as an additive to enhance polymer viscosity in cellulose acetate blend UF membranes. ${ }^{13}$

\section{Pure water permeability}

PWP is significantly affected by the molecular weight of the PEG added to the casting solution. The water permeability of the PET membrane without additives was not measured because this membrane was too fragile. ${ }^{14}$ The membrane with PEG200 (10\%) showed a PWP of $6.2 \mathrm{Lm}^{-2} \mathrm{~h}^{-1}$, whereas UF membranes containing PEG400 (10\%) and PEG600 (10\%) showed PWP values of $6.8 \mathrm{~L} \mathrm{~m}^{-2} \mathrm{~h}^{-1}$ and $7.7 \mathrm{~L} \mathrm{~m}^{-2}$ $\mathrm{h}^{-1}$, respectively. The use of PEG with a higher molecular weight in the membrane casting solution led to the production of membranes with higher water permeability. The membrane with PEG600 (30\%) exhibited the highest PWP obtained, with a value of $120 \mathrm{~L} \mathrm{~m}^{-2} \mathrm{~h}^{-1}$ (Figure 1). The presence of additives in the casting solution affects the pore size in the membranes. Ultrafiltration membrane permeability is conceptually related to the pore size..$^{15,16}$

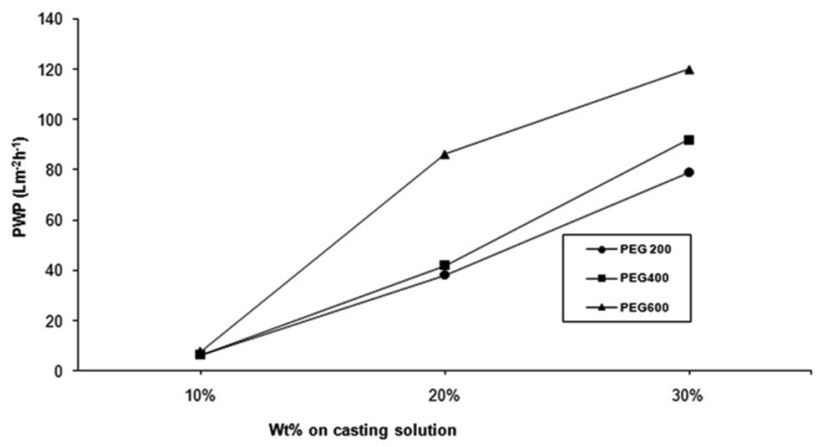

Figure 1. Pure water permeation for PET and PVP with different PEG molecular weights and concentrations (10 wt\% PVP and 20 wt\% PET)

\section{Molecular weight cut-off}

By definition, MWCO is the molecular weight of the solute that is rejected by $90 \%$ or more by the membrane. ${ }^{17,18}$ It is a pore characteristic of the membrane, and it is related to rejection for a given molecular weight of solutes. It has linear relationship with the pore size of the membrane. PET/PVP UF membranes that contained low molecular weight PEG had a low MWCO (Figure 2). As one would expect, membranes with high PWP values had a higher MWCO and smaller pores. From Figure 2a, a lower PEG concentration led to a higher solute separation, and when the molecular weight of PEG was $400 \mathrm{Da}$ (Figure 2b), the solute concentration decreased slightly. On further increasing the molecular weight of PEG, solute separation
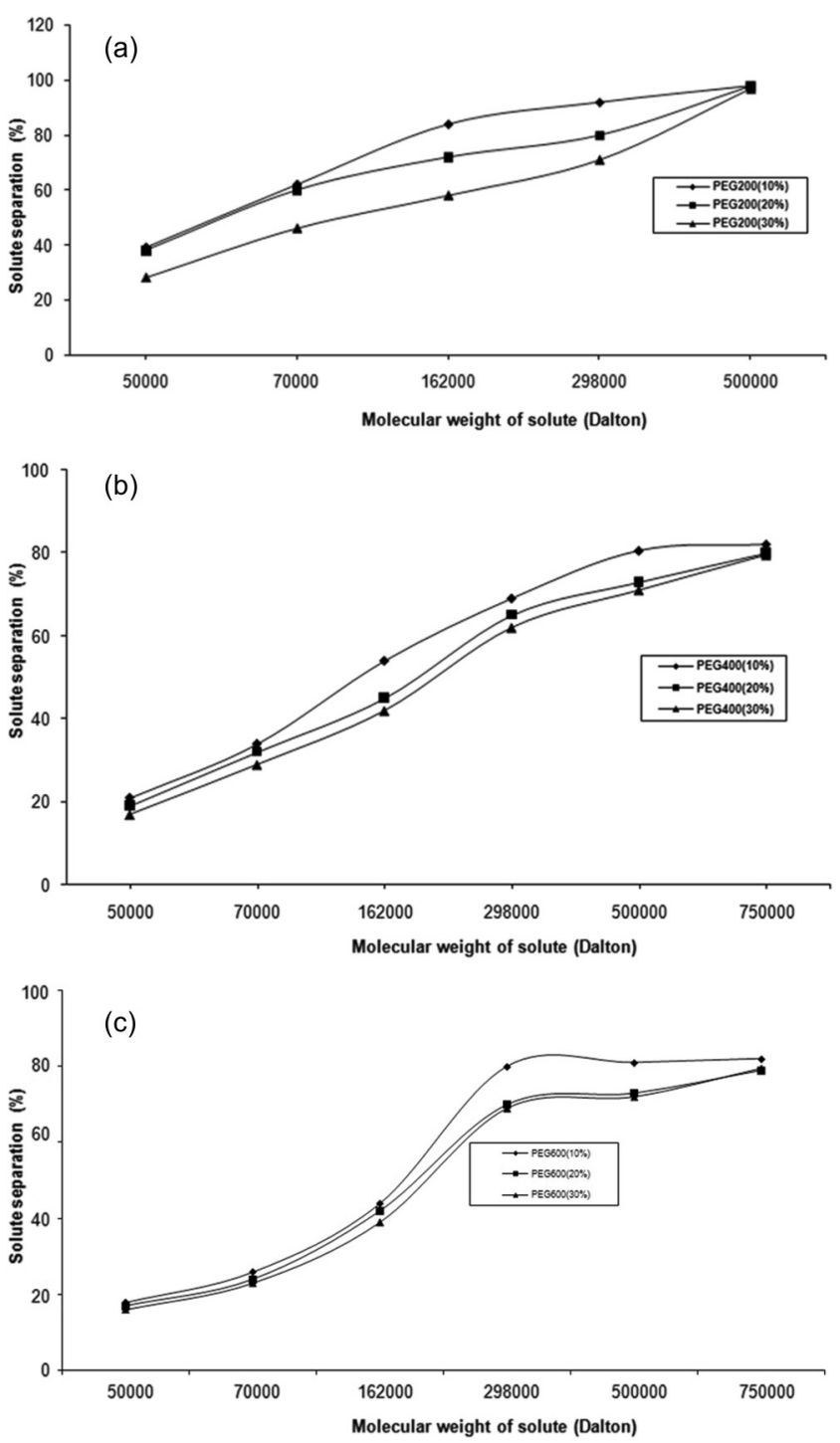

Figure 2. MWCO profile of PET/PVP UF membranes and different PEG molecular weights and concentrations: (a) $200 \mathrm{Da}$; (b) $400 \mathrm{Da}$; (c) $600 \mathrm{Da}$ 
became constant from a particular point, and there was no further difference in solute separation with changes in molecular weight thereafter. This finding clearly indicates that the UF membrane with PEG200 as additive has the lowest MWCO and mean pore size when compared to the other membranes. On the other hand, increasing the concentration of PEG400 and PEG600 in the casting solution led to an increase in the flux and a decrease in solute separation.

\section{Morphology of PET/PVP ultrafiltration membranes}

The SEM images of membrane cross sections are shown in Figures 3-5. The SEM images of PET/PVP UF membranes differ depending on additive concentrations. The SEM images show that the membranes had an asymmetrical structure with a skin layer on the top, an intermediate layer and a bottom layer.

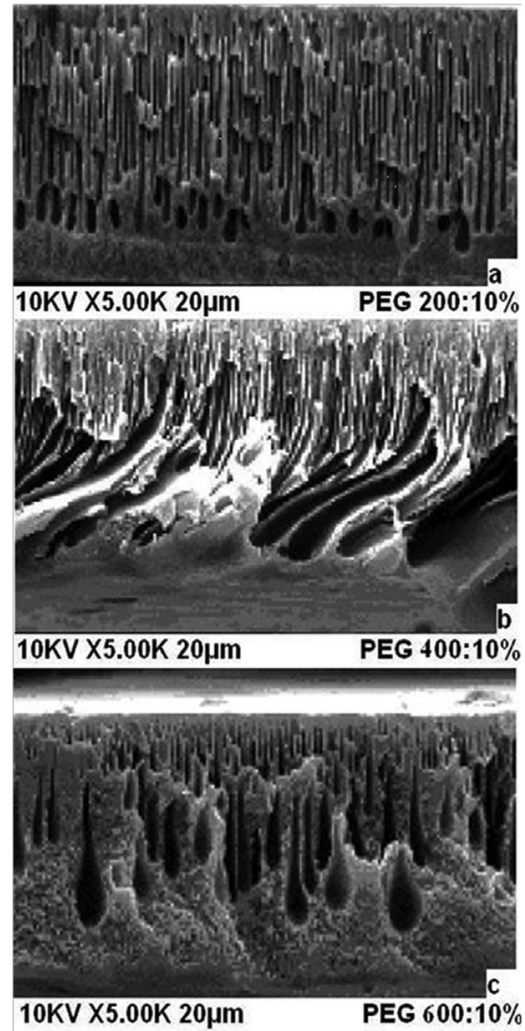

Figure 3. SEM images of the cross section of PET/PVP membranes with $10 \%$ of (a) PEG200; (b) PEG400; and (c) PEG600

The morphology of the PET with a PVP UF membrane changed because the formation of macrovoids was influenced by additive addition. From Figure 3, the size and shapes of the macrovoids were different when the solute concentration was maintained constant at $10 \%$. An increase in the molecular weight of PEG from $200 \mathrm{Da}$ to 400 Da led to an increase in the size of the macrovoids and asymmetric layer thickness (Figure 4). The solution with PVP and PEG produced membranes in which the bottom layer had a sponge-like structure, the macrovoids were very regular, and the structure had low asymmetry. ${ }^{19}$ The thin asymmetric layer probably explains the marked improvement in the rejection rate, but the thick spongy structure creates resistance, which results in rather low flux rates. On increasing the molecular weight and solute concentration to $600 \mathrm{Da}$ and $30 \%$, respectively (Figure 5), the size and shape of the macrovoids gradually changed from elongated macrovoids to tear-drop shaped macrovoids. The macrovoid size also increased on increasing the solid concentration (Figures 3a, 4a, and 5a).
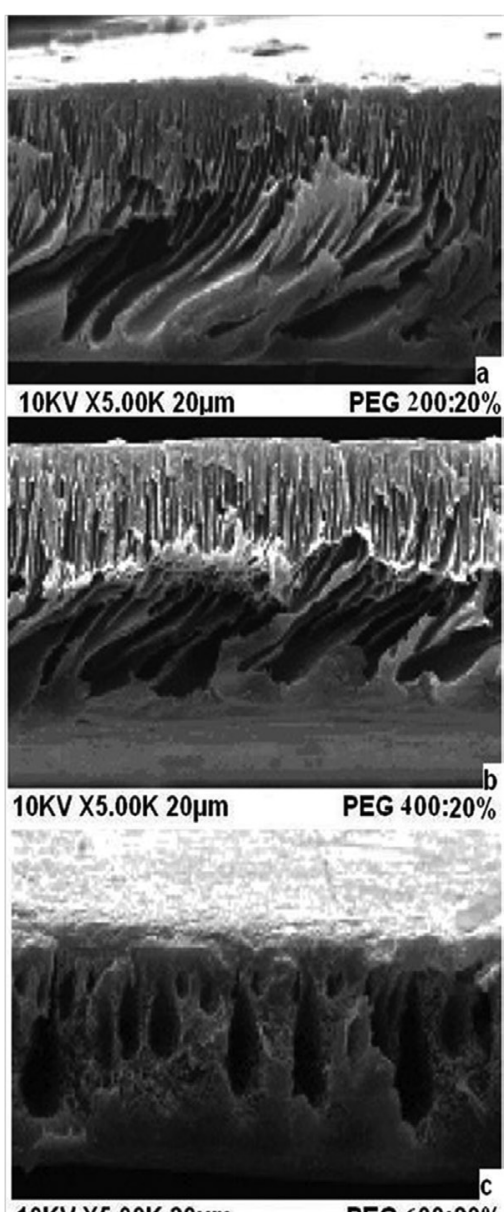

10KV X5.00K 20 $\quad$ PEG $600: 20 \%$

Figure 4. SEM images of the cross section of PET/PVP membranes with $20 \%$ of (a) PEG200; (b) PEG400; and (c) PEG600

\section{CONCLUSIONS}

This study employed unprocessed waste polyethylene terephthalate for the preparation of PET-based membranes. The addition of PEG improved the mechanical properties of the membranes and also modified the structure. The presence of PEG with different molecular weights as additives significantly affected PET and PVP membrane performance. The presence of PVP in the casting solution provided membranes with a higher flexibility. The addition of different concentrations of PEG as additives in the casting solution improved the viscosity and affected the pure water permeation rate. The pore sizes of the membranes were determined, and the ultrafiltration membrane with PEG200 as the additive has the lowest MWCO and mean pore size compared to other membranes. On the other hand, increases in the concentration of PEG400 and PEG600 in the casting solution led to increases in the flux and decreases in solute separation. The scanning electron micrographs indicate that the surface and membrane morphologies changed with the addition to the casting solution of additives with different molecular weights. The addition of PEG with a higher molecular weight increased the number and size of macrovoids, while the use of PEG with a lower molecular weight decreased the size of macrovoids in the intermediate layer. The membrane roughness increased on using additives with a higher molecular weight. The results reported here will open up a new area of research aimed at reducing environmental pollution through the reduced use of polymer raw materials and the reuse of waste PET. One of the most important uses of PET is in the manufacture of bottles, and these have caused environmental damage. PET cannot be easily 

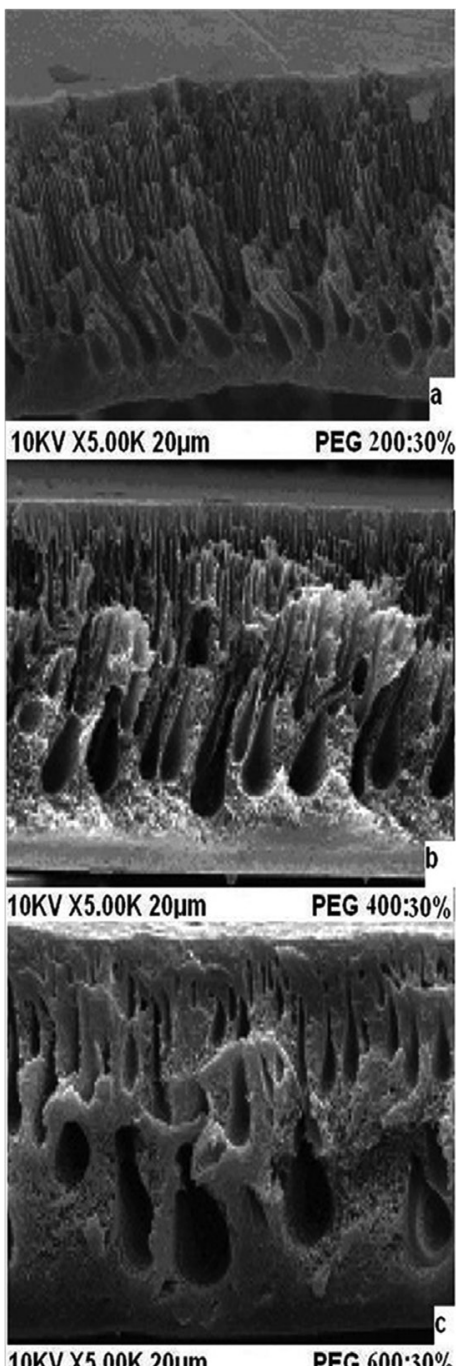

Figure 5. SEM images of the cross section of PET/PVP membranes with $30 \%$ of (a) PEG200; (b) PEG400; and (c) PEG600 recycled as a suitable method has not been developed to extract the virgin monomer from waste material. The study described here may open up a new area to address the reuse of waste PET bottles, and by the addition of suitable additives, may increase the life and tensile properties of this polymer.

\section{REFERENCES}

1. Chaturvedi, B. K.; Ghosh, A. K.; Ramachandran, V.; Trivedi, M. K.; Hanra, M. S.; Misra, B. M.; Desalination 2001, 133, 31

2. Kim, I. C.; Lee, K. H.; J. Membr. Sci. 2004, 230, 183.

3. Torrestiana-Sanchez, B.; Ortiz-Basurto, R. I.; La Fuente, E. B.; $J$. Membr. Sci. 1999, 152, 19.

4. Liu, Y.; Koops, G. H.; Strathmann, H.; J. Membr. Sci. 2003, 223, 187.

5. Xu, Z. L.; Qusay, F. A.; J. Membr. Sci. 2004, 233, 101

6. Tremblay, A. Y.; Tam, C. M.; Guiver, M. D.; Ind. Eng. Chem. Res. 1992 , 31,834 .

7. Sarboulouki, M. N.; Sep. Sci. Technol. 1982, 17, 381

8. Ramos-Olmos, R.; Rogel-Hernández, E.; Flores-López, L. Z.; Lin, S. W.; Espinoza-Gómez, H.; J. Chil. Chem. Soc. 2008, 53, 1705.

9. Golemme, G.; Bruno, A.; Manes, R.; Muoio, D.; Desalination 2006, 200,440 .

10. Anson, M.; Marchese, J.; Garis, E.; Ochoa, N.; Pagliero, C.; J. Membr. Sci. 2004, 243, 19.

11. Mahajan, R.; Burns, R.; Schaeffer, M.; Koros, W. J.; J. Appl. Polym. Sci. 2002, 86,881

12. Merkel, T. C.; Zhenjie, H.; Ingo, P.; Freeman, B. D.; Pavla, Z. M.; Macromolecules 2003, 36, 8406.

13. Li, Y.; Chung, T. S.; Microporous Mesoporous Mater. 2008, 113, 315.

14. Pandey, P.; Chauhan, R. S.; Prog. Polym. Sci. 2001, 26, 853.

15. Brunetti, A.; Scura, F.; Barbieri, G.; Drioli, E.; J. Membr. Sci. 2010, 359, 115.

16. Pechar, T. W.; Tsapatsis, M.; Marand, E.; Davis, R.; Desalination 2002, 146,3

17. Merkel, T. C.; He, Z.; Pinnau, I.; Freeman, B. D.; Meakin, P.; Hill, A. J.; Macromolecules 2003, 36, 6844 .

18. Li, Y.; Chung, T. S.; Cao, C.; Kulprathipanja, S.; J. Membr. Sci. 2005, $260,45$.

19. Burns, R. L.; Koros, W. J.; Macromolecules 2003, 36, 2374. 